\title{
O ensino da função quadrática por meio do PheT Colorado e da Engenharia Didática
}

Renata Passos Machado Vieira1 1 (D)

IFCE, Instituto Federal de Educação, Ciência e Tecnologia do Estado do Ceará, Departamento de Ensino de Ciências e Matemática, Fortaleza, Ceará, Brasil

Francisco Regis Vieira Alves ${ }^{2}(\mathbb{D}$

IFCE, Instituto Federal de Educação, Ciência e Tecnologia do Estado do Ceará, Departamento de Ensino de Ciências e Matemática, Fortaleza, Ceará, Brasil

Paula Maria Machado Cruz Catarino ${ }^{3}$

UTAD, Universidade de Trás-os-Montes e Alto Douro, Departamento de Matemática, Vila Real, Portugal

\begin{abstract}
Resumo
Neste artigo, alguns conceitos matemáticos referentes à função quadrática são investigados, com base na metodologia de pesquisa da Engenharia Didática e em suas vertentes francesas, aplicando as suas duas primeiras fases. Assim, são elaboradas duas situações didáticas de ensino, amparadas na metodologia de ensino, Teoria das Situações Didáticas, prevendo os possíveis comportamentos dos alunos diante de uma aplicação. Com tudo, é então utilizado um recurso computacional, disponível por meio de uma simulação no PheT Colorado, com o viés de facilitar o processo de ensino e aprendizagem dos estudantes em funções quadráticas, contribuindo para a construção do próprio conhecimento diante dessas metodologias utilizadas. Por fim, são realizadas análises diante de uma possível experimentação e validação, diante de um possível comportamento dos alunos, contribuindo assim para a área de Educação Matemática. Ressalta-se que as demais fases da Engenharia Didática não serão afetadas.
\end{abstract}

Palavras-chave: Engenharia Didática; Função quadrática; Recurso computacional; Teoria das Situações Didáticas.

\footnotetext{
${ }^{1}$ Mestra em Ensino de Ciências e Matemática pelo Instituto Federal de Educação, Ciência e Tecnologia do Estado do Ceará. Professora da Secretaria de Educação do Estado do Ceará. Endereço para correspondência: Av. Gen. Afonso Albuquerque Lima - Cambeba, Fortaleza - CE, 60822-325. E-mail: re.passosm@gmail.com.

2 Doutor em Ensino de Matemática pela Universidade Federal do Ceará. Professor Titular do Instituto Federal de Educação, Ciência e Tecnologia do Estado do Ceará. Endereço para correspondência: Av. Treze de Maio, 2081 - Benfica, Fortaleza - CE, 60040-531. E-mail: fregis@gmx.fr.

${ }^{3} \mathrm{PhD}$ em Matemática pela University of Essex, Reino Unido. Professora Associada da Universidade de Trás-os-Montes e Alto Douro. Endereço para correspondência: Quinta de Prados, 5001-801 Vila Real, Portugal. E-mail: pcatarino23@gmail.com.
} 


\title{
Teaching quadratic function through PheT Colorado and Didactic Engineering
}

\begin{abstract}
In this article, some mathematical concepts referring to the quadratic function are investigated, based on the Didactic Engineering research methodology and its French aspects, applying its first two phases. Thus, two didactic teaching situations are elaborated, supported by the teaching methodology, Theory of Didactic Situations, foreseeing the possible behaviors of students before an application. However, a computational resource is then used, available through a simulation at PheT Colorado, with the aim of facilitating the teaching and learning process of students in quadratic functions, contributing to the construction of their own knowledge in the face of these used methodologies. Finally, analyzes are carried out in the face of possible experimentation and validation, in view of possible student behavior, thus contributing to the area of Mathematics Education. It should be noted that the other phases of Didactic Engineering will not be affected.
\end{abstract}

Keywords: Didactic Engineering; Quadratic function; Computational resource; Theory of Didactic Situations.

\section{Enseñanza de la función cuadrática a través de PheT Colorado e Ingeniería Didáctica}

\section{Resumen}

En este artículo se investigan algunos conceptos matemáticos referentes a la función cuadrática, basados en la metodología de investigación de la Ingeniería Didáctica y sus vertientes francesas, aplicando sus dos primeras fases. Así, se elaboran dos situaciones didácticas didácticas, apoyadas en la metodología de enseñanza Teoría de Situaciones Didácticas, previendo los posibles comportamientos de los estudiantes ante una aplicación. Sin embargo, luego se utiliza un recurso computacional, disponible a través de una simulación en PheT Colorado, con el objetivo de facilitar el proceso de enseñanza y aprendizaje de los estudiantes en funciones cuadráticas, contribuyendo a la construcción de su propio conocimiento frente a estas metodologías utilizadas. Finalmente, se realizan análisis ante una posible experimentación y validación, ante el posible comportamiento del alumno, contribuyendo así al área de Educación Matemática. Cabe señalar que el resto de fases de la Ingeniería Didáctica no se verán afectadas.

Palabras clave: Ingeniería Didáctica; Función cuadrática; Recurso computacional; Teoría de las Situaciones Didácticas.

\section{Introdução}

Ao deparar-se com o conteúdo de função quadrática no Ensino Médio, os estudantes do primeiro ano da Educação Básica, necessitam revisitar certos conceitos matemáticos, oriundos do Ensino Fundamental. Com isso, inúmeras dificuldades são desmoronadas, acarretando numa problemática em relação ao ensino deste conteúdo. Quaresma e Ponte (2017), retratam que durante as décadas de 80 e 90, muitas foram as mudanças referente ao processo de ensino e aprendizagem da Matemática, devendo essas alterações tomar partida de ações ocorridas por parte dos professores.

Assim, muito tem-se pensado em relação a diferentes metodologias que poderão ser levadas para a sala de aula, visando uma melhor compreensão dos estudantes (ALVES, 2018, 2016). Ainda segundo Rodrigues e Alves (2019), aprender utilizando as situações do cotidiano e os materiais 
didáticos adequados, instigam os estudantes no processo de ensino e aprendizagem, tornando-os mais receptivos em relação a novos conhecimentos.

À vista disso, tem-se então a pergunta norteadora desta pesquisa, como sendo: como desenvolver um estudo referente à função quadrática, estimulando o estudante a resgatar os seus conhecimentos prévios adquiridos por meio de situações didáticas propostas com a utilização de recursos computacionais? Com base nisso, pode-se então traçar o objetivo geral, a saber: elaborar situações didáticas voltadas ao ensino de funções quadráticas, com base na Engenharia Didática (ARTIGUE; DOUADY; MORENO, 1995) em associação com a Teoria das Situações Didáticas (BROUSSEAU, 1972), visando explorar o lado investigativo dos estudantes, por meio de simulações no PheT Colorado.

Assim, tem-se um estudo investigativo das funções quadráticas, realizando assim uma proposta de aula com a aplicação das duas primeiras fases da Engenharia Didática, como sendo a metodologia de pesquisa, em associação à metodologia de ensino da Teoria das Situações Didáticas.

Com o viés de aprimorar ainda mais o processo de ensino e aprendizagem, tem-se então a utilização de um recurso tecnológico, uma vez que, segundo Kenski (2007), “o uso criativo das tecnologias pode auxiliar os professores a transformar o isolamento, a indiferença e a alienação com que costumeiramente os alunos frequentam as salas de aula". Logo, utiliza-se uma simulação existente no PheT Colorado, como sendo um facilitador desse processo de aprendizagem. Ressaltase que o PheT Colorado é um site, fundado em 2002 pelo Prêmio Nobel Carl Wieman, o qual consta de simulações interativas para ciência e matemática, desenvolvidas pela Universidade de Colorado Boulder.

Nas seções seguintes, é então realizado um estudo sobre a Engenharia Didática e a Teoria das Situações Didáticas, para que então sejam discutidas as suas duas primeiras fases, realizando a construção do campo epistêmico-matemático referente ao objeto de estudo da função quadrática. Dando continuidade ao processo de pesquisa, tem-se então a elaboração de duas situações-problema, diante de um plano de aula, realizado com base na simulação disponível no site do PheT Colorado.

Ressalta-se que as demais fases da Engenharia Didática não serão afetadas, uma vez que será realizada uma análise de elementos existentes, diante de uma possível análise a posteriori e validação, podendo aplicar esta pesquisa com os estudantes do primeiro ano do Ensino Médio da rede básica de ensino.

\section{Metodologia}

A metodologia de pesquisa utilizada neste trabalho, é a denominada de Engenharia Didática, estudada por Artigue (1995) na década de 80, oriunda de escolas francesas após inúmeras discussões 
referentes à Didática da Matemática (POMMER, 2013). Essa metodologia é comparada ao trabalho de um engenheiro, construindo o raciocínio lógico baseado em conhecimentos científicos, sendo estes verificados por meio de normas e regulamentações de controle, além de trabalhar com objetos mais complexos do que os depurados na ciência.

A Engenharia Didática possui o viés de avaliar e intervir nas ações educacionais (PONTE et al., 2016). Alves e Dias (2017), relatam ainda que essa metodologia "foi usada para designar/envolver um modus operandi de investigação ou ainda como uma metodologia para a análise de situações didáticas”. Almouloud e Silva (2012) ainda afirmam que:

"Esta metodologia se caracteriza por um esquema experimental baseado nas realizações didáticas em sala de aula, ou seja, sobre a concepção, realização, observação e análise de sequências de ensino, permitindo uma validação interna a partir da confrontação das análises a priori e a posteriori" (ALMOULOUD; SILVA, 2012, p. 26).

Com isso, tem-se então a Engenharia Didática, dividida em quatro fases, análise preliminar, concepção e análise a priori, experimentação e análise a posteriori e validação. Durante a fase de concepção e análise a priori, houve-se a necessidade de utilizar uma metodologia de ensino, visando elaborar algumas situações didáticas de ensino, para serem exploradas posteriormente. Tão logo, a Teoria das Situações Didáticas, ampara esse processo de elaboração das atividades propostas, voltadas ao ensino, visando aprimorar o ensino e aprendizagem dos estudantes.

Na primeira fase da Engenharia Didática, tem-se então a análise preliminar, em que, após a definição da problemática e do objeto de estudo, é então realizado um levantamento bibliográfico, construindo assim o campo epistêmico-matemático por meio de definições matemáticas que pretendese explorar nas situações didáticas de ensino. Almouloud e Silva (2012) relatam ainda que nesta fase, é feita uma "análise epistemológica do ensino atual e seus efeitos, das concepções dos alunos, dificuldades e obstáculos, e análise do campo das restrições e exigências no qual vai se situar a efetiva realização didática". Dessa forma, durante essa primeira fase é então realizado um estudo em torno da função quadrática, como forma de realizar os conhecimentos prévios dos alunos.

Na concepção e análise a priori, são selecionadas as variáveis que serão aplicadas, podendo ser microdidática, atrelada à organização de uma estrutura específica da situação utilizada na Engenharia Didática; ou macrodidática, referindo-se à estrutura global da metodologia. Assim, segundo Almouloud e Silva (2012), alguns pontos devem ser levados em consideração durante esta fase:

Descrever as escolhas feitas no nível local (relacionando-as eventualmente com as seleções globais) e as características da situação adidática desenvolvida; Analisar o que poderia estar em jogo nesta situação para o aluno, em função das possibilidades 
de ação, seleção, decisão, controle e validação que o aluno terá durante a experimentação; Prever campos de comportamentos possíveis e tentar demonstrar como a análise permite controlar seus significados e assegurar, particularmente, que se tais comportamentos esperados ocorreram, é por consequência do desenvolvimento visado pela aprendizagem (ALMOULOUD; SILVA, 2012, p. 27).

Posto isso, durante a segunda fase, é então selecionada a variável microdidática, retratando o estudo de função quadrática, com a utilização do PheT Colorado como ferramenta tecnológica de auxílio nesse processo de ensino e aprendizagem. Para isso, é então utilizada uma metodologia de ensino, que será discutida mais a frente desta seção.

A terceira fase, experimentação, é o momento em que são aplicadas as situações didáticas de ensino elaboradas na fase anterior, verificando se os objetivos e as condições para a realização da pesquisa estão conforme os parâmetros. É necessário ainda que neste momento, sejam realizados registros dos dados, para que na fase seguinte sejam analisadas essas coletas. Ressalta-se a importância de ocorrer o contrato didático, onde segundo Brousseau (1986), é o acordo realizado entre o professor e o estudante durante a aplicação da situação didática. Figueroa e Almouloud (2018), afirmam em relação ao contrato didático:

Percebe-se que os professores deixam claro que são os alunos que irão dar as respostas para as questões propostas. O papel dos alunos é interagir com o milieu e, o dos professores é de provocar os desequilíbrios necessários na fase de aprendizagem. Percebe-se que os professores provocam esses desequilíbrios a partir da dúvida, aceitando qualquer resposta dos alunos mesmo diante da resposta correta de alguns alunos. Conclui-se que esta é a estratégia didática dos professores (FIGUEROA; ALMOULOUD, 2018, p. 692).

Ferreira e Guerra (2020), refletem que durante o contrato didático, são estabelecidas as condições necessárias para que ocorra a investigação do objeto de estudo matemático, produzindo ainda situações questionáveis durante esse processo.

A última fase, análise a posteriori e validação, discute e analisa os dados coletados durante a fase anterior, sendo armazenados por meio de registros fotográficos, entrevistas, gravações de áudio e vídeo (ARTIGUE; DOUADY, MORENO, 1995). Durante essa fase, é realizado um confronto com a análise a priori, para que então sejam validados os dados de hipóteses da pesquisa, podendo ser de forma interna ou externa. A validação externa, acontece comparando os locais em que foram aplicadas as situações didáticas utilizando a Engenharia Didática, com outro local em que não utilizou essa metodologia. Na validação interna, é então analisado somente o local em que aplicou a Engenharia Didática.

De forma a complementar e dar suporte na elaboração das concepções, segunda fase da Engenharia Didática, utiliza-se então a Teoria das Situações Didáticas. Segundo Oliveira e Alves 
(2018) "a eficiência das situações didáticas com enfoque na Teoria das Situações Didáticas ocorre devida à efetivação da transposição didática e do contrato didático", em que a transposição didática "é responsável por articular elementos das dimensões epistemológica e cognitiva" (OLIVEIRA; ALVES, 2018).

A Teoria das Situações Didáticas, é uma metodologia de ensino desenvolvida por Brousseau (1986), que pretende investigar as situações didáticas de ensino e as interações entre os estudantes e o professor (ALMOULOUD, 2007). Segundo Figueroa e Almouloud (2018), "para analisar estes tipos de situações e as diferentes relações entre o saber, o aprendiz e o milieu, o processo de aprendizagem é decomposto em quatro momentos dominantes, as chamadas dialéticas de ação, formulação, validação e institucionalização".

Para isso, são elaboradas situações-problema, dispostas através de atividades, sendo então analisadas com base em suas quatro fases: ação, formulação, validação e institucionalização. Na situação de ação, os estudantes irão se deparar com a situação-problema proposta, e assim, de acordo com os seus conhecimentos prévios, irão buscar soluções para a resolução do problema. Na situação de formulação, "o estudante apresenta uma estratégia de solução, na qual ele vai elaborar conjecturas para serem validadas ou refutadas na etapa posterior" (OLIVEIRA; ALVES, 2018). É nessa fase que o estudante parte de uma solução mais geral para uma solução mais específica, formulando uma linguagem mais científica. Na fase da validação, as conjecturas serão validadas, em que segundo Teixeira e Passos (2013):

Os alunos tentam convencer os interlocutores da veracidade das afirmações, utilizando uma linguagem matemática apropriada (demonstrações); as situações de devolução, ação, formulação e validação caracterizam a situação didática, em que o professor permite ao aluno trilhar os caminhos da descoberta, sem revelar sua intenção didática, tendo somente o papel de mediador (TEIXEIRA; PASSOS, 2013, p. 165-166).

Na última fase, a da institucionalização, segundo Alves, Vieira, Silva e Mangueira (2019) “é o momento da participação efetiva do professor, para consolidar o aprendizado ou corrigir determinados entraves que os sujeitos obtiveram nas etapas anteriores" (ALVES et al., 2019). Assim, faz-se necessário verificar, por meio do professor, as soluções obtidas pelos estudantes, podendo analisar as conjecturas obtidas, além de discutir as dificuldades encontradas durante essa trajetória de resolução da situação-problema.

Ainda segundo Vieira, Alves e Catarino (2019), é importante que "durante as situações discutidas, os estudantes possam discutir as soluções erradas da atividade proposta, pois assim poderão perceber onde estão errando, chegando mais facilmente à resolução correta”. 
Com arrimo nas metodologias discutidas acima, é então iniciada a aplicação das duas primeiras fases da Engenharia Didática nas seções subsequentes, ressaltando que não haverá prejuízo das demais fases, uma vez que é realizada uma análise dos possíveis comportamentos dos estudantes, além de elementos essenciais para uma possível validação. Pode-se destacar que as duas fases da metodologia de pesquisa utilizada, retrata do processo de orientação da pesquisa, já a metodologia de ensino empregada, retrata da produção de dados.

\section{Análise preliminar}

Nesta seção, é então realizado um levantamento bibliográfico acerca do conteúdo matemático referente à função quadrática, abordado de acordo com a matriz curricular da Educação Básica do Estado do Ceará (CEARÁ, 2009), no primeiro ano do Ensino Médio. Porém, tal assunto, pode ser tratado, de maneira sucinta, nas séries anteriores do ensino fundamental. Segundo a Secretaria da Educação Básica (2006) "o estudo da função quadrática pode ser motivado via problemas de aplicação".

Para isto, é importante que o professor leve em consideração, não só o objetivo da aula a ser alcançado, destacando as possíveis dificuldades que poderão ser encontradas no local de trabalho. À vista disso, tem-se então um estudo referente ao processo de resolução de função quadrática, explorando ainda a utilização do recurso didático, de forma a propor uma aula diferenciada. Não pode-se deixar de abordar os possíveis obstáculos epistemológicos que poderão surgir durante o estudo. Para isso, realiza-se uma investigação, não só dos axiomas e conceitos matemáticos, como também de outras formas de interpretações e visualizações desta função, com o auxílio de um recurso computacional.

Fundamentado em pesquisas realizadas nos livros didáticos: Souza e Garcia (2016), Paiva (2015), Dante (2013) e Iezzi e Murakami (1993), obtidos em acervos da Matemática na Educação Básica para o Ensino Médio, observam-se dificuldades cognitivas referente ao processo de aprendizagem dos estudantes em torno da função quadrática. Ressalta-se ainda o referencial teórico, com base nos artigos e dissertações voltados ao ensino de Faria e Barbosa (2019), Rocha (2018), Maia (2007), Youschkevitch (1976).

Iniciando o estudo sobre a função quadrática, também conhecida como função do segundo grau, é muitas vezes utilizada em sala de aula na rede básica de ensino, somente por meio de livros didáticos adotados, ausentando o suporte à outros recursos oferecidos. Dessa forma, pode-se utilizar metodologias diferentes das tradicionais, visando obter uma melhor atenção dos estudantes em sala de aula (FARIA; BARBOSA, 2019). 
Após uma análise dos livros didáticos de Matemática do Ensino Médio dos autores Souza e Garcia (2016), Paiva (2015) e Dante (2013), é possível perceber que estes apresentam definições e conceitos de função quadrática, explicitados de formas distintas. Além do mais, são propostos inúmeros exercícios, apenas contextualizando este conteúdo, ausentando a utilização de recursos computacionais, onde serão possíveis obter uma forma de visualização de tal assunto matemático. Segundo uma análise de Faria e Barbosa (2019), apenas Dante (2013), aborda a definição e introdução do conteúdo, por meio de exemplos.

Percebe-se que, os livros didáticos exploram a ideia de construção do gráfico da função, por meio de construção dos pontos. É interessante que sejam alteradas as estratégias, sendo, portanto, abordados diferentes aspectos, que poderão ser trabalhados neste conteúdo matemático. Rocha (2018), em seu trabalho, discute ainda o processo histórico deste assunto, ausente em diversos livros didáticos adotados para o Ensino Médio. Youschkevitch (1976), divide a função quadrática em três etapas para o estudo histórico do seu conceito, sendo elas: antiguidade, idade média e moderna. Na primeira, as dependências existentes nessa etapa, não dividiu as noções de quantidades variáveis e de funções. Na segunda, a dependência entre as duas quantidades é descrita verbalmente. E por fim, as expressões analíticas das funções são expressas através de somas de séries infinitas (MAIA, 2007).

Dessa forma tem-se então a fórmula geral da função quadrática como sendo: $f(x)=a x^{2}+b x+c, \operatorname{com} a, b, c \in \square$ e $a \neq 0$. Assim, o seu gráfico gerado é formado por uma parábola como pode-se observar na Figura 1. Com isso, percebe-se a construção do gráfico da função $f(x)=x^{2}+x-2$ plotado no software GeoGebra. Pode-se visualizar que a imagem toca no eixo $\mathrm{x}$, nos pontos -2 e 2, sendo assim as raízes dessa função.

Figura 1 - Gráfico função quadrática

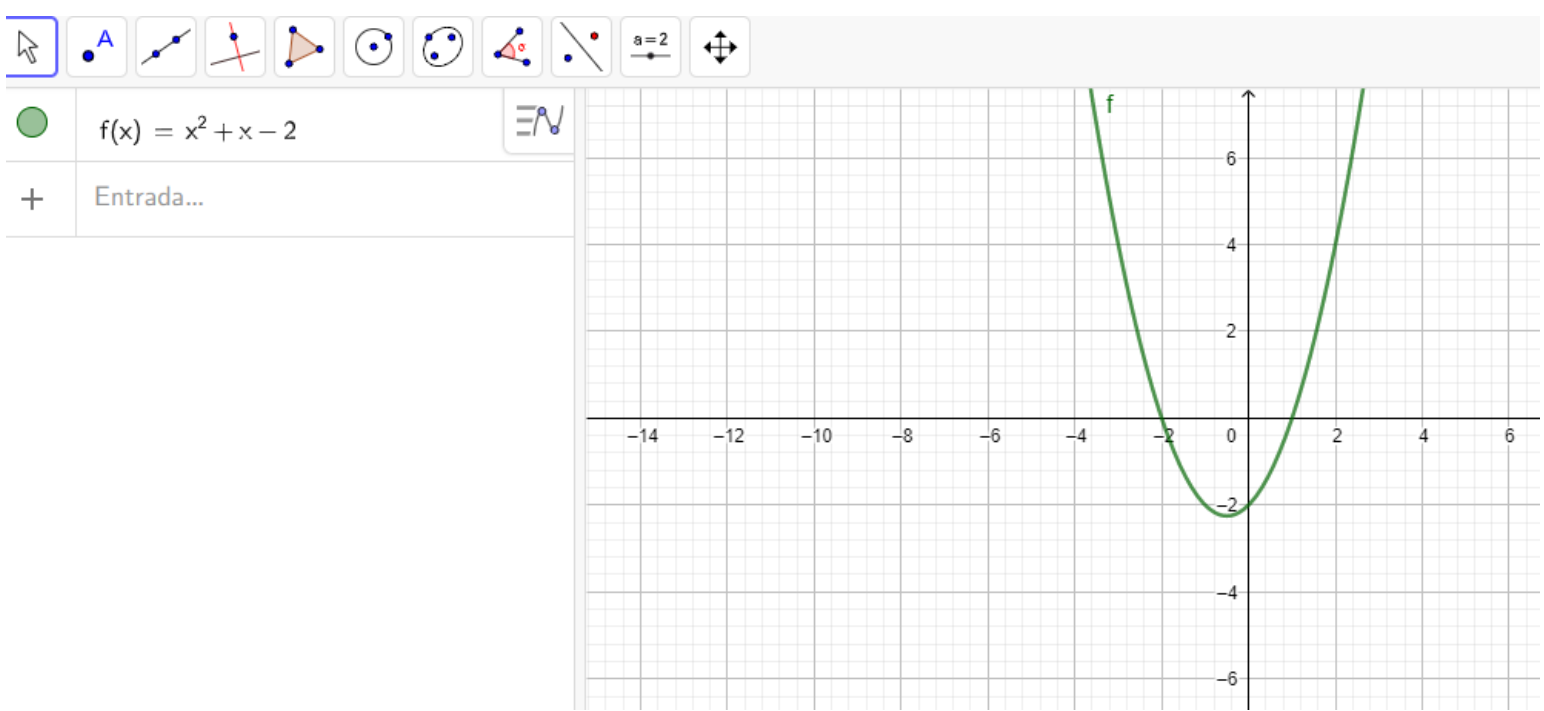

Fonte: Elaborado pelos autores. 
Um mapa conceitual é então desenvolvido para aprimorar o processo de ensino e aprendizagem dos estudantes em relação à este assunto (ver Figura 2). De fato, a utilização do mapa conceitual, permite que o professor obtenha um feedback em relação ao entendimento do conteúdo pelos alunos.

Figura 2 - Mapa Conceitual

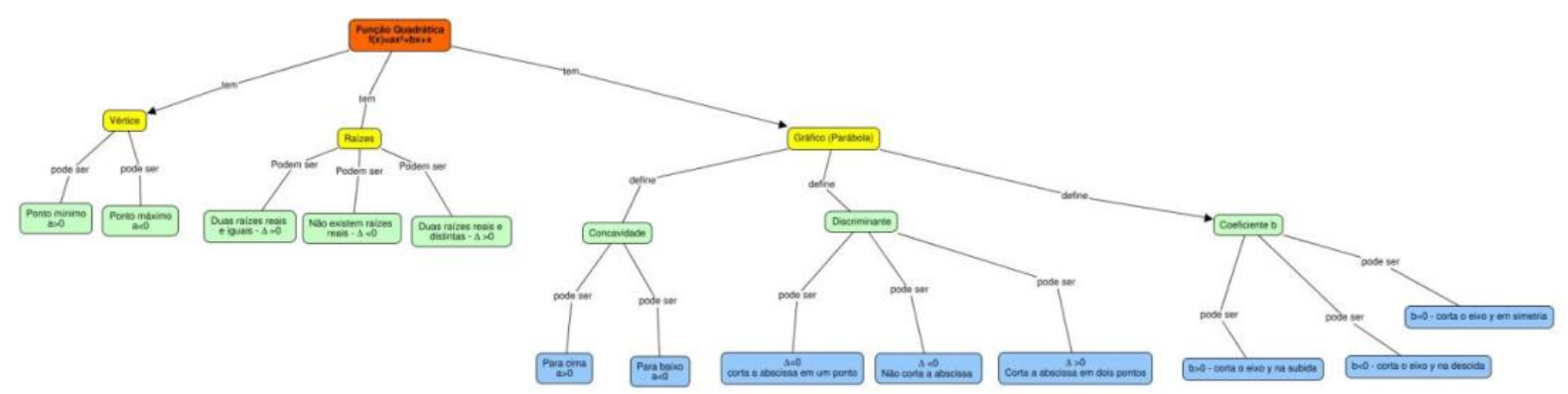

Fonte: Elaborado pelos autores.

Diante de uma abordagem epistemológica e didática, são então, selecionados alguns assuntos referentes à construção dos gráficos da função quadrática e as suas variáveis, e elaboradas algumas situações didáticas, com o auxílio da simulação Gráfico de Quadráticas, disponível na plataforma PheT Colorado.

\section{Concepção e análise a priori}

Durante esta fase, o professor realiza a elaboração, descrição e analisa as atividades propostas diante da situação didática de ensino. Neste momento, é importante também que os comportamentos dos estudantes sejam analisados pelos professores, sendo esse um intermediador durante o processo de aprendizagem. Desse modo, o professor tem a função de agir numa dimensão epistemológica, cognitiva e didática, estabelecendo elementos favoráveis, ou não, para o desenvolvimento do estudante em seu conhecimento lógico (ALMOULOUD; SILVA, 2012).

Com o viés de estimular o pensamento cognitivo do estudante, por meio do desenvolvimento teórico matemático e vivenciado pelas situações didáticas de ensino, houve-se então a necessidade de aplicar uma metodologia de ensino, sendo então a Teoria das Situações Didática (BROUSSEAU, 1972). Para isso, são elaboradas duas situações-problema, propostas aos estudantes, com arrimo nas fases de ação, formulação, validação e institucionalização.

Antes de mais nada, será utilizada a simulação Gráfico de Quadráticas (ver Figura 3), a qual apresenta em sua interface gráfica quatro opções de acesso, sendo essas: Explore, Forma Padrão, Forma Vértice e Foco e Diretriz. Esta simulação matemática está disponível no PheT Colorado com o nome de Gráfico de Quadráticas. A opção Explore possui a facilidade de modificar os valores dos coeficientes a,b e c da função quadrática, permitindo ainda analisar o comportamento do gráfico 
gerado. A opção Forma Padrão, é a que será utilizada nesta pesquisa, permitindo atribuir valores para os coeficientes da função quadrática, escrita em sua forma geral. Com isso, é possível que sejam visualizados os eixos de simetria, equação, vértice, raízes, equações e coordenadas. Na Forma Vértice, é mostrado o eixo de simetria, vértice, equações e coordenadas por meio de sua forma canônica. O Foco e Diretriz, possui a possibilidade de modificar os valores dos coeficientes por meio da ferramenta controle deslizante. Com esse recurso, os estudantes poderão estudar diversas formas de visualizar e manipular os gráficos da função quadrática, facilitando o processo de ensino e aprendizagem.

Figura 3 - Simulação Gráfico de Quadráticas

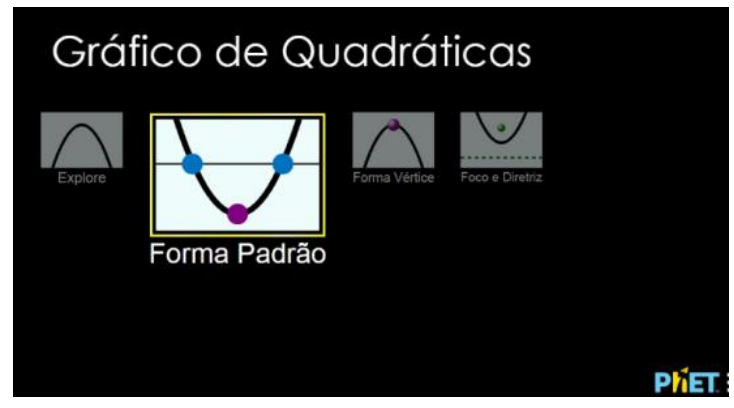

Fonte: PheT Colorado

Dessa forma, tem-se as seguintes situações-problema:

Situação-problema 1: Com base na fórmula geral da função quadrática, $f(x)=a x^{2}+b x+c$, com $a, b, c \in \square$ e $a \neq 0$, faça uma análise do comportamento do coeficiente a quando $a>0, a<0$. Utilize o recurso Gráfico de Quadráticas para melhor análise.

Fase da Ação: Nesta fase, os estudantes deverão buscar em seus conhecimentos prévios, o conceito de função quadrática, permitindo lembrar o motivo pelo o qual o valor de $a$ não permite ser igual a 0 , sendo pelo fato da função ser quadrática, uma vez que ao igualar a zero a função passa a ser afim.

Fase da Formulação: Utilizando a simulação Gráfico de Quadráticas, do PheT Colorado, os estudantes deverão selecionar a opção Forma Padrão, para então analisar o comportamento do coeficiente $a$. Assim, é necessário que sejam fixados valores para os demais coeficientes ( $b$ e $c$ ), e posteriormente, realizar a manipulação da ferramenta seta, disponível para o coeficiente $a$, movimentando-a para cima e para baixo, afim de analisar o comportamento deste coeficiente. Assim, deverão perceber que quando o valor de $a$ é positivo, a concavidade será voltada para cima e quando o valor de $a$ é negativo, a concavidade é voltada para baixo.

Fase da Validação: Nesta fase, é então validado o comportamento do coeficiente $a$ da função quadrática, por meio da simulação Gráfico de Quadráticas. Logo, conforme mostrado na Figura 4, 
eISSN: 2526-9062

tem-se que quando o $a>0$, a concavidade é voltada para cima, além de permitir também o ângulo de abertura da parábola.

Figura 4 - Comportamento de coeficiente $a$ positivo

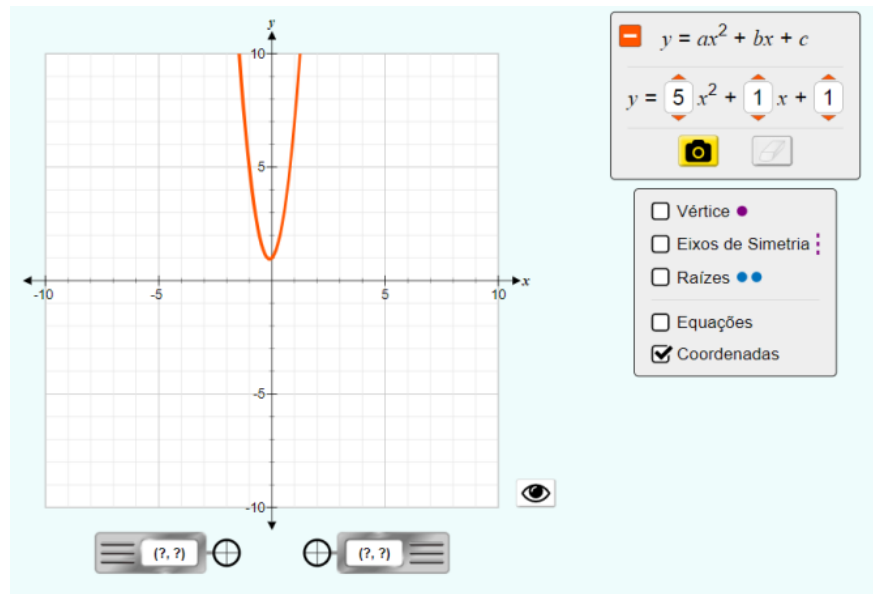

A $⿴$ 田

PlîE:

Fonte: PheT Colorado

Na Figura 5, tem-se então que quando o $a<0$, a concavidade da parábola é voltada para baixo, além de o valor numérico desse coeficiente ser relacionado com a abertura do ângulo do gráfico. Logo, quanto maior o valor de $a$, menor a abertura.

Figura 5 - Comportamento de coeficiente $a$ negativo

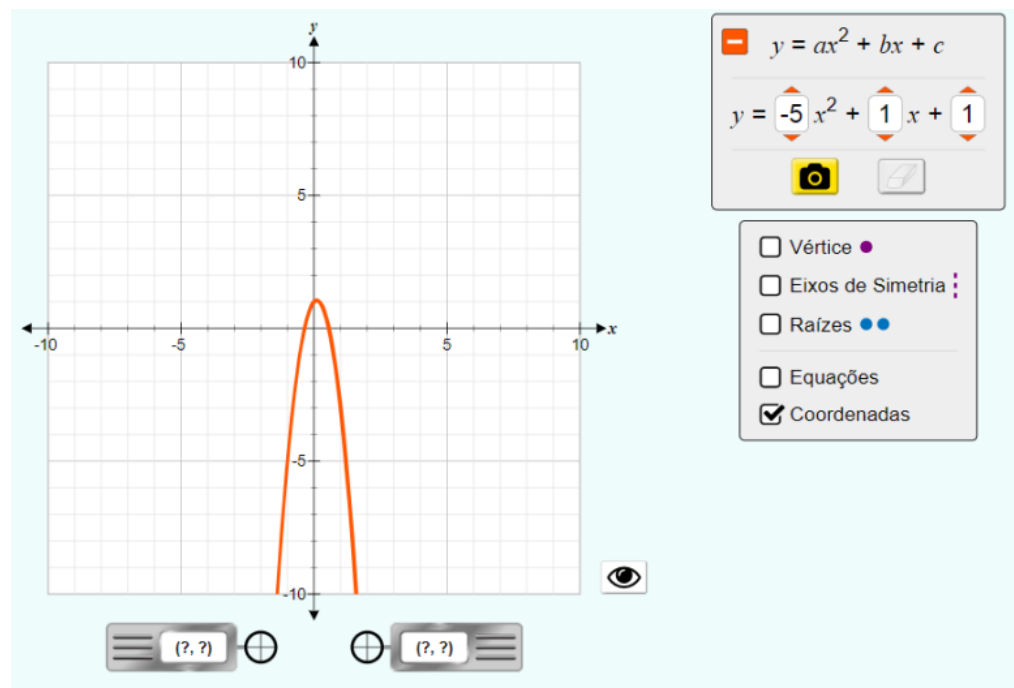

\section{企 Plï日.}

Fonte: PheT Colorado

Fase da Institucionalização: Momento em que o professor retoma à atividade proposta, analisando as discussões realizadas pelos estudantes, além de verificar se essas estão corretas. É nesse momento que o professor revela que a situação aplicada tem por objetivo identificar o comportamento do coeficiente $a$ da função quadrática, verificando assim que esse permite a alteração da concavidade 
eISSN: $2526-9062$

da parábola (voltada para cima $a>0$ ou para baixo $a<0$ ), bem como o seu respectivo ângulo de abertura.

Situação-problema 2: Com a utilização da simulação Gráfico de Quadráticas, analise e discuta o comportamento dos coeficientes $b$ e $c$ da função quadrática, descrita em sua fórmula geral.

Fase da Ação: Os estudantes deverão inserir valores para o coeficiente $b$, e fixar valores para $a$ e $c$, percebendo assim o comportamento desses para $b<0, b>0$ e $b=0$. De modo semelhante, o mesmo procedimento deve ser realizado para o coeficiente $c$, observando assim o seus respectivos comportamentos.

Fase da Formulação: Após as simulações, os estudantes deverão perceber que, ao variar o coeficiente $b$, esse inclina a parábola após o corte sob o eixo $y$. Ao alterar os valores do coeficiente $c$, é indicado o local em que a parábola irá "cortar" o eixo $y$.

Fase da Validação: Por meio do recurso, os estudantes deverão validar que quando $b<0$, temos que a parábola segue para a direita, a partir do ponto de corte do eixo $y$. Com isso o gráfico desce (Figura 6).

Figura 6 - Comportamento de coeficiente $b$ negativo

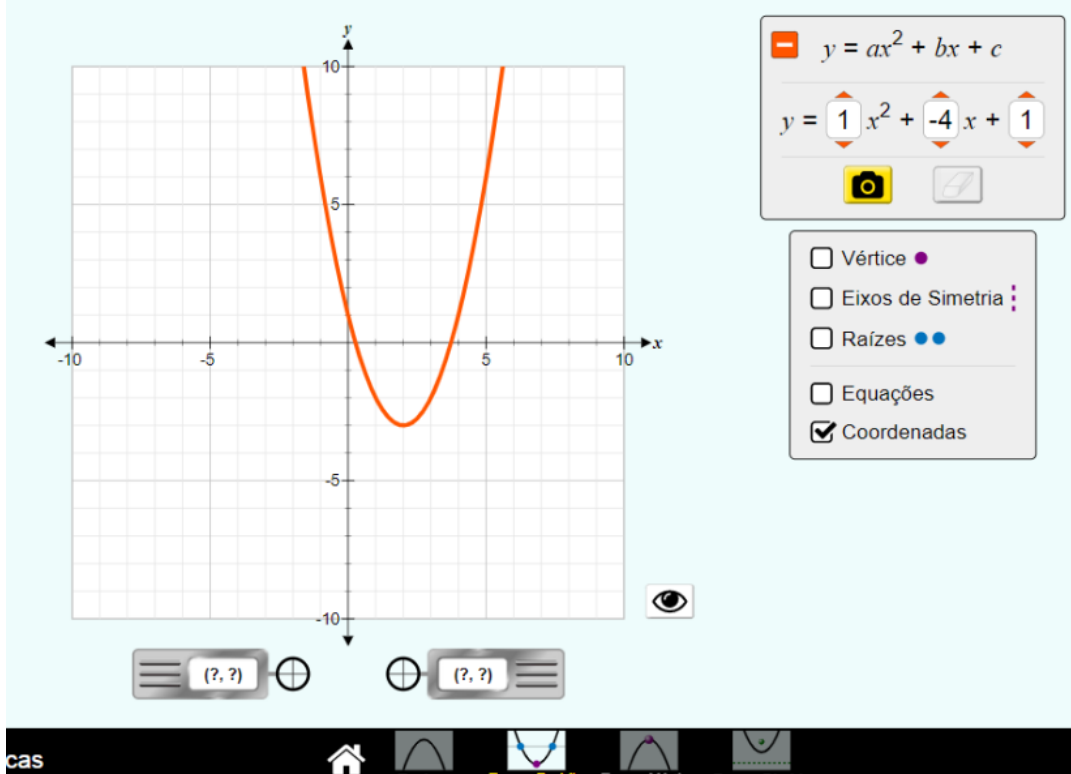

Fonte: PheT Colorado

Quando $b>0$, a parábola sobe após o corte do eixo $y$, seguindo para a esquerda (Figura 7). 
eISSN: 2526-9062

Figura 7 - Comportamento de coeficiente $b$ positivo
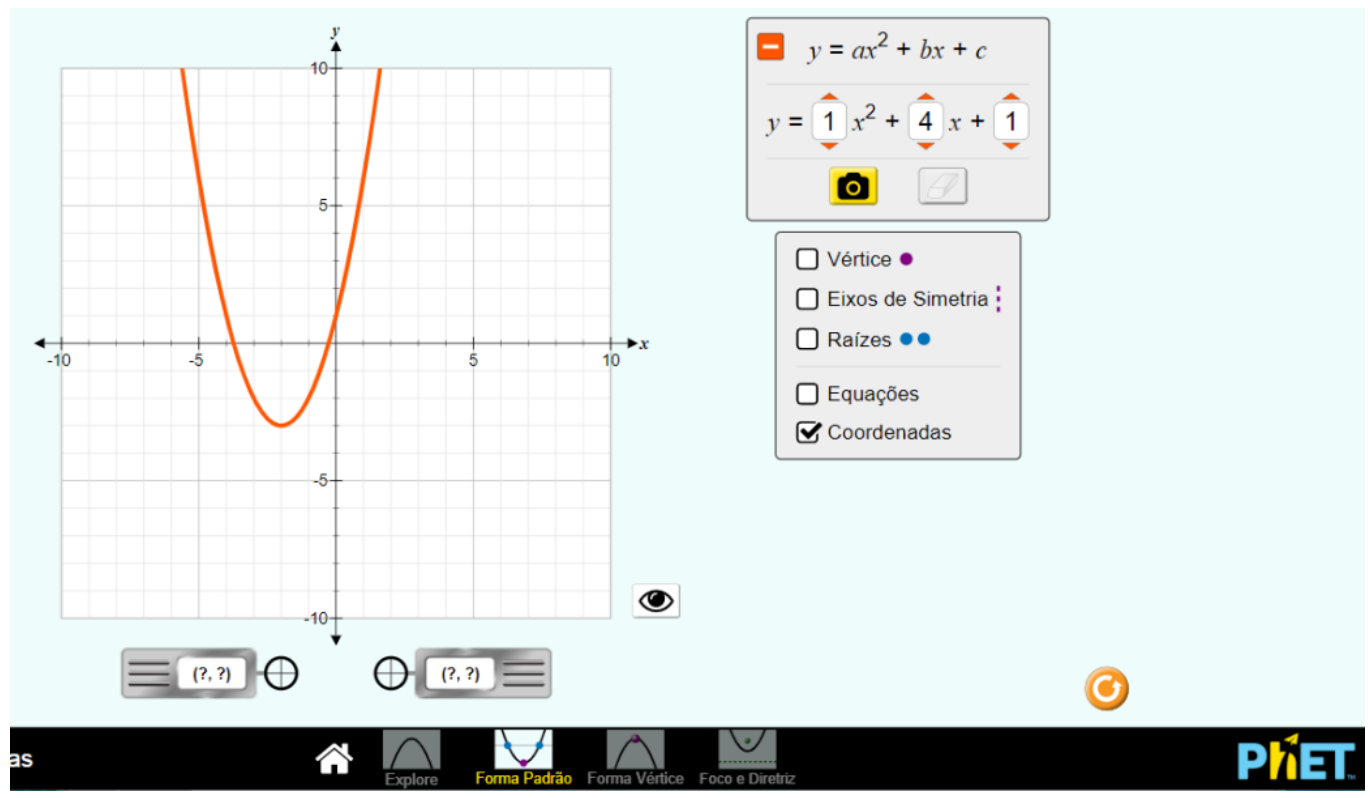

Fonte: PheT Colorado

Ao possuir o valor de $b=0, \operatorname{logo}$ após cortar o eixo $y$, a parábola seguirá reta (Figura 8).

Figura 8 - Comportamento de coeficiente $b$ nulo

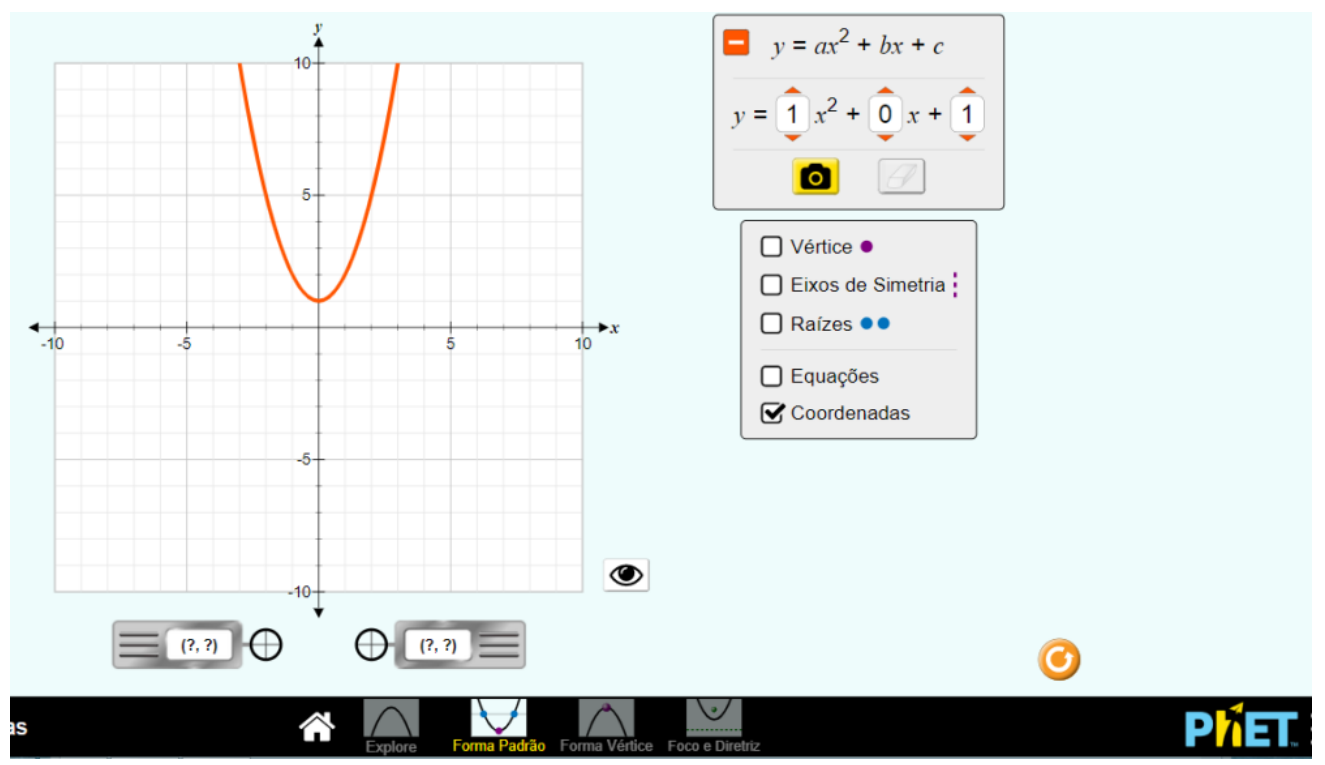

Fonte: PheT Colorado

Analisando o comportamento de $c$, tem-se que para $c>0$, a parábola corta o eixo $y$ acima da origem (Figura 9). 
eISSN: 2526-9062

Figura 9 - Comportamento de coeficiente $c$ positivo

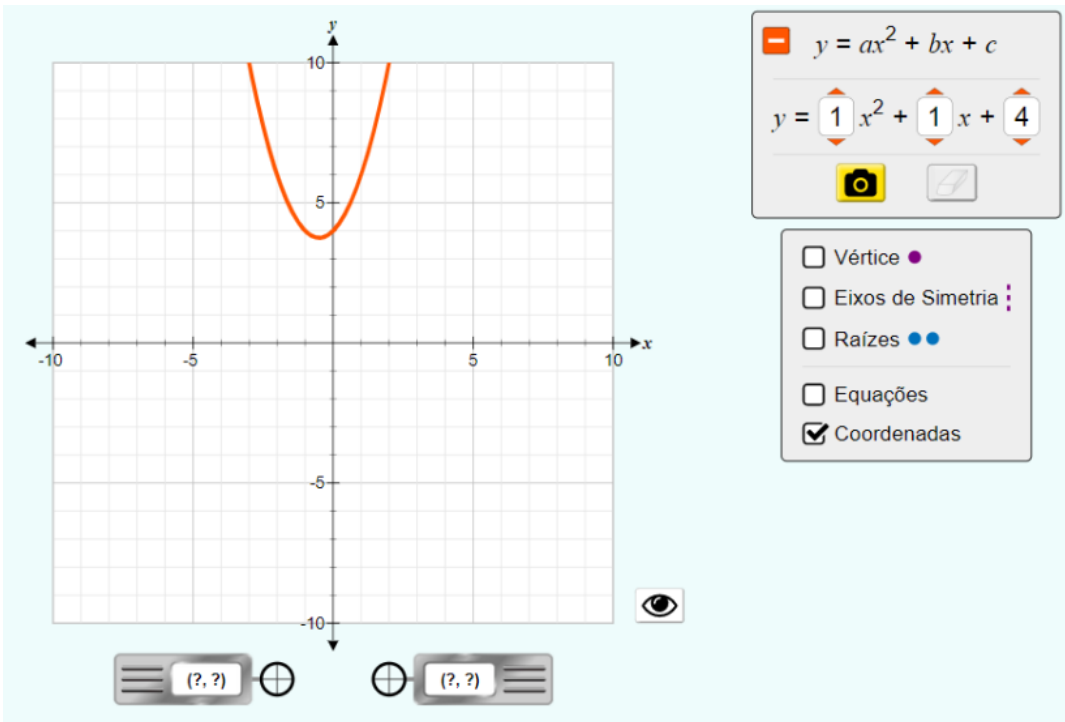

Aิ

Fonte: PheT Colorado

Para $c<0$, a parábola corta o eixo $y$ abaixo da origem (Figura 10).

Figura 10 - Comportamento de coeficiente $c$ negativo

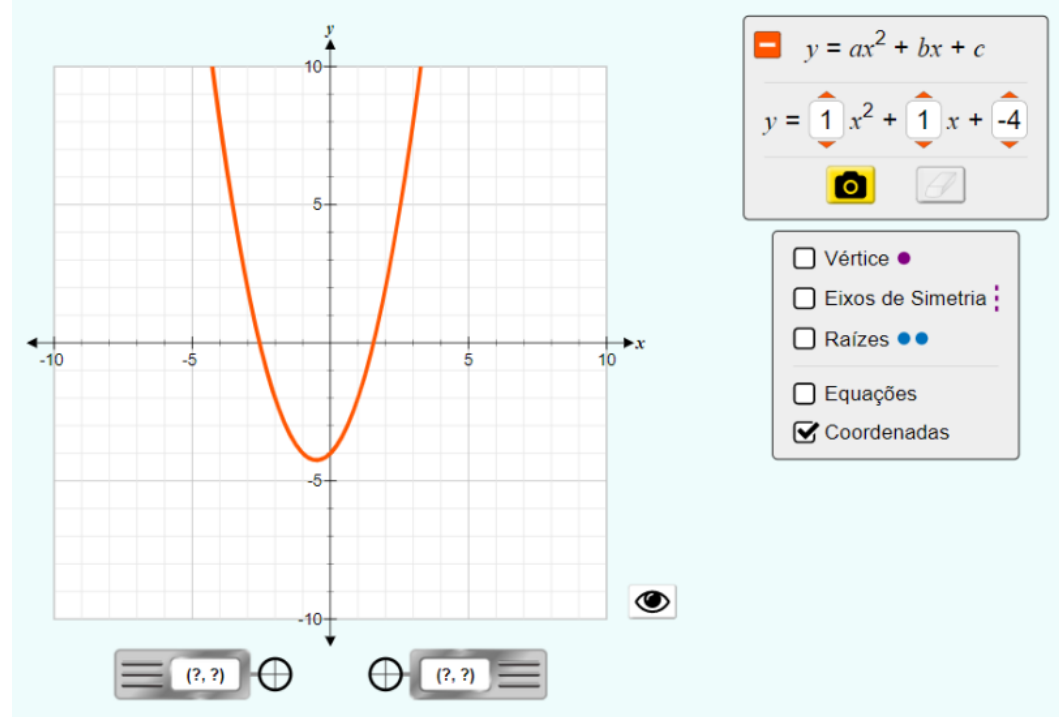

A $\triangle Q N$

Fonte: PheT Colorado

E por fim, para $c=0$, a parábola corta o eixo $y$ na origem (Figura 11). 
Figura 11 - Comportamento de coeficiente $c$ nulo

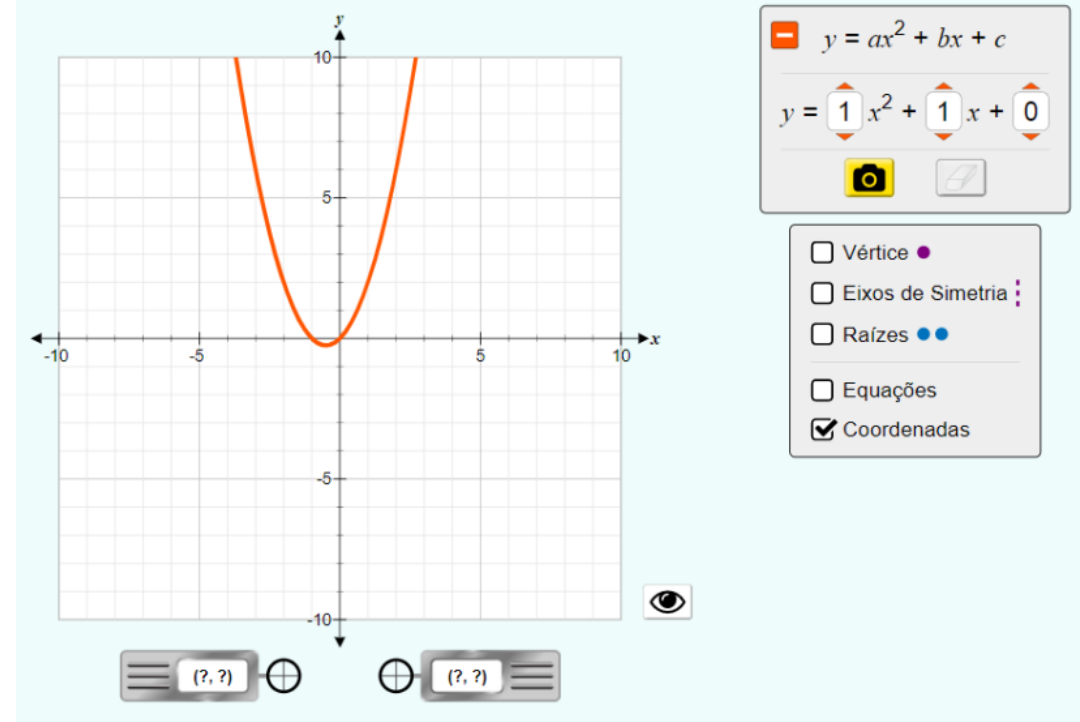

\section{金}

Fonte: PheT Colorado

Fase da Institucionalização: Ao retornar a atividade, o professor deverá revelar o seu objetivo, sendo este o comportamento dos coeficientes $b$ e $c$ da função quadrática. Assim, o coeficiente $b$ é responsável pela inclinação da parábola após passar pelo eixo $y$. Já o coeficiente $c$ indica o local em que a parábola "corta" o eixo $y$.

Com tudo, pode-se perceber que essa atividade visa uma aplicação para turmas do primeiro ano do Ensino Médio da rede básica de ensino. Tão logo, foram realizadas previsões dos possíveis comportamentos dos estudantes, fundamentada nas fases da Teoria das Situações Didáticas.

\section{Elementos para uma possível análise a posteriori e validação}

Ajustes locais e correções devem ser levados em consideração durante a coleta dos dados empíricos, assim, conforme relata Almouloud (2007), na etapa da análise a posteriori da Engenharia Didática, realiza-se uma junção dos resultados obtidos, explorando aqueles que podem contribuir para uma melhoria dos conhecimentos didáticos dos estudantes. Já no momento da validação, os dados coletados são comparados com os resultados esperados. No caso desta pesquisa, sugere-se uma comparação de uma experimentação com a utilização da tecnologia, e a outra sem o uso de recurso computacional.

Feito isso, consideram-se, ainda, as variáveis microdidáticas, explorando uma análise em relação aos coeficientes da função quadrática. Assim, é observado o caráter do comportamento desses coeficientes, diante de variações na parábola. Propõem-se outras situações-problema, abordando as 
demais opções existentes na simulação utilizada, de forma a explorar outros assuntos, tais como o vértice da parábola, zero da função e entre outros.

É importante que o professor observe se os estudantes estão conseguindo obter uma evolução do raciocínio inferencial para caso contrário, sejam tomadas medidas resolutivas diante do obstáculo identificado. Durante as resoluções, os estudantes poderão formar grupos, facilitando assim as discussões, o processo de ensino e aprendizagem, e as dificuldades existentes no local de aplicação.

Destaca-se que apesar da simulação utilizada ser de fácil manuseio, podem existir dificuldades em torno de qual variável fixar para a análise do comportamento das outras. Assim, o estudante poderá optar por fixar a variável errada, acarretando em conclusões errôneas. Porém esse fato, deve ser descoberto pelos estudantes, não havendo a inserção do professor em determinados momentos.

Segundo Figueroa e Almouloud (2018), “a característica principal da aula é o diálogo entre os professores e os alunos, em que todos têm a oportunidade de participar, sendo que alguns respondem, questionam e, outros observam”. Assim, é importante que o professor observe se a aplicação está ocorrendo de forma correta, não ocasionando o protagonismo em determinados estudantes como construtores de seu próprio conhecimento, havendo assim um crescimento mútuo de todos os estudantes envolvidos.

\section{Considerações finais}

Este trabalho realizou um estudo sobre funções quadráticas em torno dos seus coeficientes, fundamentado na metodologia de vertente francesa, Engenharia Didática. Assim, foram desenvolvidas atividades propostas referente ao respectivo conteúdo matemático, com o viés de instigar o lado intuitivo e investigativo dos estudantes do primeiro ano do Ensino Médio, utilizando ainda um recurso computacional como ferramenta de auxílio.

Com arrimo na problemática identificada, foi possível traçar o objetivo geral da pesquisa, alcançando com êxito. Com tudo, nas seções anteriores, percebeu-se um breve estudo referente à Engenharia Didática e a Teoria das Situações Didáticas, sendo então discutidas as suas respectivas fases. Dando continuidade a este processo, foi então realizada uma análise preliminar, elencando conceitos matemáticos sobre a função quadrática, destacando pontos relevantes, realizando assim os conhecimentos prévios dos alunos. Com base nesses conhecimentos, foi possível elaborar duas situações didáticas de ensino em torno do conteúdo de função quadrática.

A segunda fase foi então baseada na elaboração de atividades propostas, utilizando uma simulação disponível no PheT Colorado, para facilitar o processo de aprendizagem sobre o comportamento dos coeficientes da função quadrática. Durante essa fase, houve a necessidade de utilizar a metodologia de ensino, analisando os possíveis comportamentos dos alunos diante de cada 
uma de suas fases. É importante ainda destacar, que os possíveis comportamentos dos estudantes foram analisados, evidenciando alguns elementos diante de uma possível análise a posteriori e validação.

Por fim, trata-se a proposta discutida neste artigo, como sendo de suma importância, ao tratar de alternativas metodológicas de pesquisa e ensino, em torno do ensino de função quadrática com o auxílio do PheT Colorado. Ressalta-se que a discussão até então realizada, não se encontra finalizada, podendo buscar alternativas de melhorias, para um futuro, aplica-las em turmas da educação básica de ensino, evidenciando assim os resultados obtidos nessa pesquisa. De fato, tem-se a contribuição dessa pesquisa para a área de Educação Matemática, com conteúdo oriundo da educação básica.

\section{Referências}

ALMOUlOUD, S. Fundamentos da Didática da Matemática. São Paulo: UFPR, 2007.

ALMOULOUD, S. A.; SILVA, M. J. Engenharia didática: evolução e diversidade. Revemat: Revista Eletrônica de Educação Matemática, v. 7, n. 2, p. 22-52, 2012.

ALVES, F. R. Engenharia Didática para a generalização da sequência de Fibonacci: uma experiência num curso de licenciatura. Educação Matemática Pesquisa, v. 18, n. 1, p. 61-93, 2016.

ALVES, F. R. Engenharia Didática para o Ensino de Variável Complexa: Visualização de Conceitos Relacionados ao Processo Matemática de Integração. Alexandria-Revista de Educação em Ciência e Tecnologia, v. 11, n. 2, p. 3-29, 2018.

ALVES, F. R.; DIAS, M. A. Formação de professores de matemática: um contributo da engenharia didática (ED). REVEMAT, v. 12, n. 2, p. 192-209, 2017.

ALVES, F. R. et al. Ensino de ciências e educação matemática 3. Organizador Felipe Antonio Machado Fagundes Gonçalves. Capítulo 2 - Engenharia Didática para o ensino da sequência de Padovan: um estudo da extensão para o campo dos números inteiros. Ponta Grossa, PR: Atena Editora, 2019.

ARTIGUE, M. Ingeniería didáctica en educación matemática. Un esquema para la investigación y la innovación en la enseñanza y el aprendizaje de las matemáticas. Bogotá: una empresa docente \& Grupo Editorial Iberoamérica, 1995.

BÁSICA, S. Ciências da natureza, matemática e suas tecnologias/Secretaria de Educação Básica. Brasília: Ministério da Educação, 2006.

BROUASSEAU, B. A. Fibonacci Numbers and Geometry. The Fibonacci Quartely, v. 10, n. 3, p. 249-255, 1972.

BROUSSEAU, G. La relation didactique: Le milieu. Paris: Actes de la IVème Ecole d'Eté, 1986.

CEARÁ, S. Metodologias de Apoio: matrizes curriculares para ensino médio. Fortaleza, Ceará: Coleção Escola Aprendente - Volume 1, 2009. 
DANTE, L. R. Contexto e Aplicações. São Paulo: Ática, v. 1, 2013.

FARIA, P. J.; BARBOSA, L. D. A Função Quadrática nos livros didáticos de Matemática no Ensino Médio. VIII Seminário de Iniciação Científica do IFNMG, p. 1-3, 2019.

FERREIRA, R. S. do R.; GUERRA, R. B. Formação inicial de professores que ensinam matemática e o sistema de numeração decimal. Revista de Estudos e Pesquisas sobre Ensino Tecnológico, v. 6, Edição Especial, p. 1-17, 2020.

FIGUEROA, T. P.; ALMOULOUD, S. A. O Milieu e o Contrato Didático - Análise de uma Aula Demonstrativa do Círculo da Matemática do Brasil. Acta Scientiae, v. 20, n. 4, p. 687-706, 2018.

IEZZI, G.; MURAKAMI, C. Fundamentos de Matemática Elementar. São Paulo: Atual, v. 1: Conjuntos e soluções, 1993.

KENSKI, V. M. Educação e Tecnologias: O novo ritmo da informação. Campinas - SP: Papirus, 2007.

MAIA, D. Função quadrática: Um estudo didático de uma abordagem computacional. São Paulo: PUC - Mestrado em Educação Matemática, 2007.

OLIVEIRA, R. R.; ALVES, F. R. Uma Investigação dos Polinômios Bivariados e Complexos de Fibonacci Amparada na Engenharia Didática: uma Aplicação da Teoria das Situações Didáticas. Acta Scientiae, v. 21, n. 3, p. 170-193, 2018.

PAIVA, M. Matemática Paiva. São Paulo: Ática, v. 2, ed. 3, 2015.

POMMER, W. M. A Engenharia Didática em sala de aula: Elementos básicos e uma ilustração envolvendo as Equações Diofantinas Lineares. São Paulo: S. N, 2013.

PONTE, J. P. et al. Investigação baseada em design para compreender e melhorar as práticas educativas. Quadrante, v. XXV, n. 2, p. 77-98, 2013.

QUARESMA, M.; PONTE, J. P. Dinâmicas de aprendizagem de professores de Matemática no diagnóstico dos conhecimentos dos alunos num estudo de aula. Quadrante, v. 26, n. 2, p. 43-68, 2017.

ROCHA, E. B. Abordagem da função quadrática por meio da sua forma canônica: um estudo de caso numa escola pública de Juazeiro - BA. Juazeiro - BA: Universidade Federal do Vale do São Francisco - Mestrado Profissional em Matemática em Rede Nacional - PROFMAT, 2018.

RODRIGUES, G. R.; ALVES, F. J. C. Avaliação do uso de uma sequência didática no ensino de matrizes através da programação em blocos por um grupo focal. Revista de Estudos e Pesquisas sobre o Ensino Tecnológico, v. 5, n. 12, p. 30-50, 2019.

SOUZA, J.; GARCIA, J. Contato Matemática. São Paulo: Ática, 2016.

-FE, v. 21, n. 39, p. 155-168, 2013.

TEIXEIRA, P. J.; PASSOS, C. C. Um pouco da teoria das situações didáticas (tsd) de guy brousseau. Zetetiké 
eISSN: $2526-9062$

VIEIRA, R. P.; ALVES, F. R.; CATARINO, P. M. Uma Exploração da Sequência de Padovan num curso de Licenciatura em Matemática. Indagatio Didactica, v. 11, n. 4, p. 261-279, 2019.

YOUSCHHKEVITCH, A. The concept of function. Archive for History of Exact Sciences, v. 16, n. 1, p. 37-85, 1976. 